\title{
Dos sociedades y una sola revista. Ante una nueva etapa
}

- I motor inicial de nuestra revista en su inicio hace tres años fue crear un punto de encuentro en lengua castellana, donde los apasionados de la ecocardiografía y otras técnicas de imagen tuviesen un foro común, con preferencia de exposición de casos clínicos. De esta idea nació RETIC, Revista de Ecocardiografía y otras Técnicas de Imagen Cardíaca.

Sin duda estábamos en lo cierto al creer que ante la gran avalancha informática editorial mundial existía un hueco para que nuestra revista se dedicase básicamente a la exposición de casos clínicos de la especialidad de imagen cardíaca. La idea era muy oportuna y lo confirmaba el hecho de que, al año del nacimiento de RETIC, otras potentes Sociedades copiasen o, al menos, replicasen nuestro proyecto, con la creación de revistas específicas para la presentación de casos diagnosticados con las distintas técnicas de imagen cardíaca.

El nacimiento de cualquier proyecto científico implica el esfuerzo y la imaginación de un grupo de "locos" de la imagen que, con su empeño, con las horas robadas a su trabajo y familia, lo ponen en marcha. Desde esta página queremos dar la gracias a todos los socios de ambas Sociedades Científicas que hicieron realidad el nacimiento de esta idea. Durante estos tres años la revista se ha estructurado básicamente en tres áreas:

- Revisiones de temas globales.

- Casos clínicos que forman el núcleo de la Revista.

- Una pequeña área de trucos prácticos para la realización de estudios ecocardiográficos.

Sin duda la revista ha tenido aspectos muy positivos en esta primera etapa, y el más importante fue demostrar que somos capaces de poner en marcha un proyecto como este, al mismo nivel de cualquier proyecto similar de otras lenguas. Contamos, por supuesto, con el trabajo espectacular de CTO y su maravilloso y profesional equipo editorial que han dado soporte a esta idea. Sin duda, ningún proyecto desarrollado recientemente con editoriales de habla castellana o inglesa cumple la calidad y recursos editoriales que CTO ha marcado en RETIC.

Una vez puesta en marcha la revista RETIC y tras estos noveles tres años de andadura, es también el momento de hacer una revisión crítica, que sirva para corregir errores, mejorar aspectos que probablemente se descuidaron y relanzar con fuerza a la revista a su nueva etapa de fin de adolescencia e inicio de la madurez. Creemos que existen dos puntos mejorables en nuestra revista que se han valorado y detectado después de muchas reuniones entre los presidentes de ambas Sociedades Científicas, y que queremos transmitir, porque son la base que permite implicar a todos en esta nueva etapa de RETIC:

1. El núcleo de trabajo en RETIC será compartido aún más igualitariamente entre SISIAC y SEIC, lo que ocasiona que ambas sociedades estén más directamente implicadas en la labor de trabajo del día a día de la revista.

2. Esto se traducirá en el hecho que la revista RETIC se relacione fuertemente con los socios de SEIC y con los de SISIAC, considerándola como "su" revista, transmitiendo una idea fundamental: "Dos sociedades científicas para un proyecto editorial común para sus socios".

Por ello, la junta ejecutiva de ambas sociedades ha pensado en un relanzamiento de la idea original: una revista útil de casos clínicos para dos sociedades con un interés común. De ahí que se hayan realizado algunos cambios que queremos transmitir:

- La revista estará dirigida por dos directores: uno designado por SEIC (presidente en ejercicio) y otro por SISIAC (past-president inmediato) con similares obligaciones.

- Se crea el Núcleo Director Editorial de RETIC: serán el alma de la interacción entre las dos sociedades, siendo responsables de la recolección de los contenidos, su análisis, su modificación de ser necesario y aprobación para su posterior trabajo editorial en CTO. El núcleo está compuesto por 2 miembros designados por SEIC y 2 miembros por SISIAC, quienes trabajarán mancomunadamente en el proyecto. Para esta primera etapa los miembros de SEIC serán José Juan Gómez de Diego y Pedro Azcárate y por parte de SISIAC Alma Sthela Arrioja y Mario Vargas.

- Se hacen cambios importantes en el consejo editorial de la revista, entre los que se destaca brevemente la creación y renovación del nuevo Consejo Asesor, que estará dirigido por dos directores: uno designado por SEIC (Dr. Arturo Evangelista, presidente del Campus SEIC-CTO), y otro por SISIAC (Dr. Ricardo Pignatelli, presidente en ejercicio), y tendrá 10 miembros por cada una de las dos sociedades. 
Esta nueva etapa que se inicia con ilusión y sin escatimar esfuerzo alguno, no tendría sentido sin la participación de TODOS LOS MIEMBROS de ambas sociedades. Por ello, desde aquí, os solicitamos vuestra ayuda en este relanzamiento que, sin duda, arribará a buen puerto.

Muchas gracias a todos,

Miguel Ángel García Fernández

Salvador Spina

Directores de RETIC

Citar como: García-Fernández MA, Spina S. Dos sociedades y una sola revista. Ante una nueva etapa. Rev Ecocar Pract (RETIC). 2020 (Mar); 3 (1): I-II. doi: 10.37615/retic.v3n1a1

Cite this as: García-Fernández MA, Spina S. Two societies and one journal. A new era. Rev Ecocar Pract (RETIC). 2020 (Mar); 3 (1): I-II. doi: 10.37615/retic.v3n1a1 